\title{
1 - Literatura juvenil: para ler e ensinar
}

\author{
Benedito Antunes
}

\section{SciELO Books / SciELO Livros / SciELO Libros}

ANTUNES, B. Literatura juvenil: para ler e ensinar. In: A literatura juvenil na escola [online]. São Paulo: Editora Unesp Digital, 2019, pp. 11-20. ISBN: 978-85-9546-331-8. https://doi.org/10.7476/9788595463318.0002.

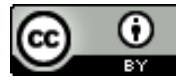

All the contents of this work, except where otherwise noted, is licensed under a Creative Commons Attribution 4.0 International license.

Todo o conteúdo deste trabalho, exceto quando houver ressalva, é publicado sob a licença Creative Commons Atribição 4.0.

Todo el contenido de esta obra, excepto donde se indique lo contrario, está bajo licencia de la licencia Creative Commons Reconocimento 4.0. 


\section{1 \\ LITERATURA JUVENIL: PARA LER E ENSINAR ${ }^{1}$}

Abordam-se neste livro alguns aspectos do ensino da literatura associado à discussão do conceito de literatura juvenil. Como se sabe, a literatura sempre teve uma relação tensa com a escola. Enquanto, de um lado, a função formadora que todos reconhecem nela tem motivado sua inserção nos currículos, de outro, o uso propriamente pedagógico que essa função enseja parece conspurcar seu valor estético. Essa tensão se agrava ainda mais quando obras criadas especialmente para fins pedagógicos, isto é, para estimular a leitura e a formação de crianças e jovens, aspiram à condição literária. No tocante à literatura infantil, a questão parece mais assentada, pois há um mercado consolidado para esse subgênero, que atende a um público pré-escolar e alunos dos primeiros anos do ensino fundamental. Já com relação à chamada literatura juvenil, as posições são mais controversas. Há desde os que não reconhecem sua existência até os que defendem sua especificidade literária, independentemente de seu uso escolar.

Parte-se aqui do pressuposto de que, se a boa literatura infantil é reconhecida como um subgênero acessível às crianças e, tal como a literatura em geral, proporciona prazer estético e forma em sentido

1 Este texto incorpora partes que originalmente pertenciam aos ensaios "Dois livros" e "Ser jovem em dois tempos". 
amplo, para além de eventuais intenções pedagógicas mais pontuais, também a literatura juvenil deve ser contemplada pela discussão a respeito de sua especificidade, baseada em parâmetros similares, ou seja, que a considerem como acessível a um público jovem e igualmente capaz de formar para a vida. $\mathrm{O}$ entendimento de que livros dedicados às crianças podem ser valorizados por um adulto é referendado por ninguém menos que Antonio Candido, que, já nos tempos em que escrevia rodapés, admitia:

As histórias que apelam para a nossa imaginação agem sobre nós como as que encantam as crianças de tal forma que se nem todo livro de adulto serve para menino, todo bom livro de criança serve para um adulto. $\mathrm{O}$ grande, o bom conto infantil é, portanto, o que vale igualmente para adultos. (Candido, 1986, p.329)

Não se pode ignorar, porém, que esse terreno é sempre instável e sujeito às mudanças históricas. Por isso, a posição mais confortável seria ignorar a discussão e tratar a literatura como um gênero sem adjetivos, e o leitor, como aquele que lê o que lhe agrada. Mas, do ponto de vista do educador, essa atitude é improdutiva. Enquanto individualmente há leitores precoces e motivados inclusive para a leitura de clássicos universais ou de obras mais densas, na média de uma situação escolar nem sempre se observa interesse pela literatura e muito menos pela leitura mais exigente, que demanda horas de concentração e esforço. Em outras palavras, mesmo entre crianças e jovens, sempre houve interesse pela leitura de autores que eram também lidos pelos adultos. O que se apresenta hoje como problema, especialmente no âmbito escolar, é a conquista do jovem para a leitura, de modo a inseri-lo no processo de formação de um leitor literário.

Parece haver consenso entre os especialistas que a boa literatura tanto para crianças quanto para jovens é aquela que emancipa, isto é, proporciona o verdadeiro prazer estético, com variantes emocionais, expressivas e críticas capazes de se transformarem em conhecimento. Dessa perspectiva, a literatura com fins pedagógicos explícitos, voltada para a transmissão de determinado saber pontual, em geral 
orientado por uma visão ideológica, representaria o oposto da boa literatura. É evidente que, apesar da clareza da formulação, na prática os limites nem sempre são claros. O que pensar, nesse sentido, da obra de Monteiro Lobato, que pode ser considerada pedagógica em inúmeras passagens, mas se revela emancipadora por excelência?

Trata-se de um paradoxo que pode ser mais claramente observado na chamada literatura juvenil, que, por se dirigir a um público mais maduro, nem sempre tem sua especificidade reconhecida. Aliás, essa questão está associada à própria dificuldade de se estabelecer a faixa etária desse público. Apesar disso, a designação de uma literatura própria para os jovens tem sido discutida pelos estudiosos e é largamente utilizada pelo mercado editorial e pela escola, bem como por escritores, bibliotecas, leitores, "guias de leitura" e instituições que premiam obras desse subgênero literário (Aguiar, [s.d.], p.10). De fato, a questão está posta e deve ser aprofundada. Vale reiterar que essa discussão interessa principalmente ao educador, preocupado com a formação do leitor literário, pois da formação do leitor em geral o mercado editorial sabe cuidar muito bem.

\section{A identificação do público juvenil}

Por isso, antes de passar à análise das obras supostamente juvenis, é preciso tecer algumas considerações sobre o público preferencial desses livros, visando definir sua possível faixa etária. Para efeitos práticos, poderia ser considerado jovem o indivíduo que frequenta os dois ou três últimos anos do ensino fundamental e o primeiro ou o segundo ano do ensino médio, com idade entre 12 e 16 anos, quando ele não é mais criança, mas ainda não é considerado adulto. Essa condição recomendaria a leitura de livros adequados à sua capacidade de compreensão e ao interesse que a temática lhe poderia despertar. É comum a preocupação com a idade do leitor nas listas de livros indicados para crianças e jovens. Maria da Glória Bordini e Vera Teixeira de Aguiar, por exemplo, no já clássico Literatura: a formação do leitor (1988), apresentam em apêndice uma 
alentada relação de autores e obras recomendados para leitura na educação básica, divididos em três faixas etárias: 1) de 7 a 10 anos; 2) de 11 a 14 anos; 3) de 15 a 17 anos. Na verdade, são as faixas utilizadas pelas autoras para exemplificar as unidades de ensino dos métodos propostos no livro: currículo por atividades, currículo por áreas e currículo por disciplinas. Mesmo sem uma análise mais acurada das obras relacionadas para cada faixa, é possível perceber que a variação contempla sobretudo a sua complexidade. Assim, na primeira faixa, correspondente ao currículo por atividades, predominam contos de fada e histórias infantis, com destaque para clássicos como Hans Christian Andersen, Irmãos Grimm, Charles Perrault, Monteiro Lobato e nomes contemporâneos como Ana Maria Machado, Tatiana Belinky, Mary e Eduardo França, Ruth Rocha, Sylvia Orthof, além de textos breves de Cecília Meireles, Carlos Drummond de Andrade, Marina Colassanti, Lygia Bojunga Nunes. Na segunda faixa, correspondente ao currículo por áreas, já aparecem, ao lado de autores claramente identificados com essa idade, como Pedro Bandeira, Marcos Rey, Sérgio Capparelli, clássicos universais traduzidos ou adaptados, como Júlio Verne, Mark Twain, Cervantes, e nacionais, como Monteiro Lobato, Ana Maria Machado, Lygia Bojunga Nunes, Mário Quintana, Carlos Drummond de Andrade, Aluísio Azevedo. Na terceira faixa, correspondente ao currículo por disciplinas, prevalecem os autores da literatura adulta, como José de Alencar, Manuel Antônio de Almeida, Machado de Assis, Raul Pompeia, Carlos Drummond de Andrade, Erico Verissimo, Rubem Braga, Fernando Sabino, Luis Fernando Verissimo, o Rubem Fonseca de Bufo ES Spallanzani, além de clássicos universais traduzidos, poemas de Brecht etc.

A relação apresentada está baseada na convicção de que "a idade do leitor influencia seus interesses: a criança, o adolescente e o adulto têm preferências por textos diferentes" (Bordini; Aguiar, 1993, p.19). A questão, dessa forma, consiste em observar a natureza da adequação de diferentes textos à idade do leitor, o que, aliás, varia conforme a época e o contexto social. Há quem diga, por exemplo, que Machado de Assis não deveria ser lido por jovens, menos por 
uma questão de censura do que de condições de aproveitamento, que só ocorreria de forma mais intensa quando o leitor estivesse mais maduro. De qualquer modo, já se reconhece como inadequado propor a um jovem do ensino fundamental que leia Memórias póstumas de Brás Cubas se o objetivo for cativá-lo para a boa literatura. A complexidade do livro poderá afastá-lo da leitura porque há nos dias de hoje formas mais acessíveis de satisfação da necessidade de ficção e fantasia. Igualmente, não se propõe que uma criança de 10 anos leia um texto que, embora formalmente acessível, possa chocá-la pela violência, como Feliz ano novo, de Rubem Fonseca, da mesma forma que não é aconselhável propor nem mesmo no ensino médio a leitura coletiva de Pornopopeia, de Reinaldo Moraes, seja pelo tratamento explícito do consumo de drogas e da prática sexual, seja pela própria dramaticidade existencial tematizada no livro. Ou seja: a preocupação com um gênero especificamente voltado para os jovens nasce e se desenvolve no âmbito educacional, buscando-se oferecer a eles uma leitura adequada à sua maturidade intelectual e emocional. Essa adequação tinha, no início, uma sobrecarga formadora, que acabava empobrecendo a natureza literária das obras. Nos dias atuais, busca-se um equilíbrio, advogando para a literatura destinada a essa faixa etária uma qualidade estética que a aproxime da verdadeira literatura, capaz de emancipar sem subestimar a inteligência e a sensibilidade do leitor nem criar constrangimentos de ordem institucional, familiar ou mesmo pessoal.

Reconhecida a necessidade de adequação entre textos e leitores, cabe caracterizar a literatura juvenil, apontando os traços mais recorrentes em obras normalmente destinadas ao público dessa faixa etária. De modo geral, todos os traços parecem situar-se na assimetria entre o escritor adulto e o leitor jovem. Essa assimetria faz que o escritor se dirija a alguém que não dispõe do mesmo conhecimento ou experiência que ele, levando-o a mostrar-se condescendente com seu destinatário ou dar-lhe explicações e conselhos. Sem pretender esgotar a questão, são lembrados a seguir alguns traços que podem ser verificados nos livros analisados a seguir: 
a) Cumplicidade. Com a preocupação de manter a atenção do leitor e ganhar sua simpatia, o narrador procura estabelecer certa intimidade entre os dois, fazendo comentários e observações para sugerir que é alguém próximo da pessoa que o lêe no momento.

b) Linguagem agradável. Para não entediar nem cansar seu leitor, o escritor usa uma linguagem simples, com expressões contemporâneas, que se aproxime do modo de falar dos jovens, seja por meio de gírias, seja pelas referências a ícones de seu universo.

c) Humor. Esse recurso é usado como forma de manifestar distanciamento em relação a determinados valores ou práticas que mereceriam reparos ou pelo menos alguma desconfiança, além, claro, de envolver o leitor num jogo que apela para sua inteligência.

d) Aventuras. Traço comum aos best-sellers, elas servem para dotar a narrativa de muitas ações, realistas ou fantasiosas, que contribuem para prender a atenção de um leitor pouco acostumado a reflexões ou movimentos mais intimistas.

e) Trama policial e mistério. Assim como no caso anterior, enredos centrados no desvendamento de um crime ou no esclarecimento de situações misteriosas também favorecem o envolvimento do leitor.

f) Erotismo. A referência ao amor e mesmo a práticas amorosas também alimenta a curiosidade e o interesse do leitor pouco atento. Assim como o anterior, é um recurso para prender a atenção, independentemente de outras qualidades narrativas.

g) Informação cultural. Ao lado da constante referência aos ícones culturais da juventude, que também contribui, no plano da linguagem, para criar identificação com o leitor, a menção a aspectos mais amplos da cultura é usada como forma de enriquecer e ampliar o seu universo cultural.

h) Bom exemplo. De forma direta ou apenas sugerida, sancionar bons comportamentos e atitudes corretas do ponto de vista humano, social e político é uma maneira de contribuir 
para a formação do jovem leitor. Com a mesma preocupação, procura-se não endossar práticas condenáveis, como o uso de drogas, a perversão sexual, os atos de violência e os preconceitos sociais, religiosos, raciais, entre outros.

Evidentemente, esses traços podem ser encontrados em qualquer obra literária. É provável, porém, que sua presença, ampla ou parcial, desde que percebida como intencional, tenda a diminuir o valor da obra, por torná-la subordinada a um objetivo externo à natureza estética, que deveria proporcionar uma experiência criativa e livre de cerceamentos de qualquer espécie. Surge, assim, uma questão que talvez esteja no centro da discussão da literatura juvenil: como avaliar uma obra que se caracteriza como juvenil e, ao mesmo tempo, aspira à condição de arte literária? Uma possível resposta apontaria para a identificação de um andamento que deixasse transparecer traços como esses sem que eles representem o tom dominante, permitindo acima de tudo uma interação de ordem estética com o leitor jovem e considerando os outros aspectos, inclusive o propósito formativo, como decorrência dessa interação, e não como um princípio programático.

\section{A literatura quando jovem}

Quando se trata da literatura "adulta”, ou sem adjetivos classificatórios, esses pontos não merecem atenção especial. Normalmente, o autor se expressa por um narrador próximo de sua personalidade artística; o público-alvo, por sua vez, supondo que ele seja pensado previamente, estará igualmente próximo de seu universo, seja ele da cultura erudita, da cultura popular ou da cultura de massa; quanto ao universo representado, é sempre o mais amplo possível. A produção literária ou artística exige uma reflexão particular sobre os elementos envolvidos no processo de comunicação quando nele se verifica alguma assimetria, geralmente sinalizada por um qualificativo que se acrescenta à literatura: sertaneja, regionalista, 
negra, feminista, infantil, juvenil. Por essa razão, é preciso insistir em algumas considerações a respeito de subgêneros literários que se caracterizam principalmente pela definição de seu público-alvo.

A título de exemplo, tome-se, do ponto de vista da produção literária, o primeiro dos casos mencionados anteriormente, em que normalmente um autor erudito procura dar voz a um sertanejo que não domina nem a língua culta nem a capacidade de efabular no plano erudito. Se a solução formal não superar a distância cultural entre o universo do autor e o de sua personagem, hipótese em que o qualificativo parece mais justificar-se, a fissura inevitavelmente surgirá na forma de algum descompasso, que pode ir do mero artificialismo linguístico ao mais acabado preconceito. É o que sucede, no entender de Antonio Candido, com Coelho Neto quando insiste em distinguir o narrador culto da personagem sertaneja por meio da "injustificável dualidade de notação da fala" (Candido, 2002, p.89). Com isso, ao contrário do propósito do autor, que era o de recuperar o homem marginalizado, observa-se um regionalismo de "sentido reificador", que "pode funcionar [...] como representação desumanizada do homem das culturas rurais" (ibidem, p.90). Por outro lado, ainda conforme Antonio Candido, o regionalismo pode ter um sentido humanizador quando o autor encontra uma "solução linguística adequada" (ibidem), por meio da qual "o universo do homem rústico é trazido para a esfera do civilizado" (ibidem, p.92). No seu exemplo, isso é conseguido por Simões Lopes Neto, que "começa por assegurar uma identificação máxima com o universo da cultura rústica, adotando como enfoque narrativo a primeira pessoa de um narrador rústico" (ibidem, p.90), o que lhe permite utilizar "um estilo castiço registrado segundo as convenções da norma culta", mas sabiamente adaptado, de modo a conseguir um nível eficiente de estilização (ibidem, p.92).

O mesmo vale para autores inicialmente considerados regionalistas, como Graciliano Ramos e Guimarães Rosa, que adotam recursos similares aos apontados por Antonio Candido a propósito de Simões Lopes Neto para representar universos sociais e culturais distantes dos seus. Logram, com isso, criar personagens rústicas sem 
cair na armadilha da assimetria mencionada anteriormente, atingindo um nível de elaboração formal que tende a dispensar o adjetivo particularizador. Recorde-se, a esse propósito, o funcionamento do narrador de Vidas secas, examinado por Alfredo Bosi (1988) em estudo sobre os dois autores. Ainda que o narrador de Graciliano mantenha uma nítida distância ideológica em relação às personagens, caracterizada por uma consciência crítica, de historiador, que não se ilude com perspectivas idealistas sobre o andamento da história, consegue, graças ao recurso estilístico, aproximar-se delas, manifestando simpatia pelas suas causas e se solidarizando com seus dramas. Assim, a possível motivação regionalista de sua obra torna-se elemento secundário e não impede que ela seja compreendida universalmente, por leitores de diferentes tempos e lugares.

Deslocando-se o foco para o campo da comunicação, em que a preocupação se concentra no público-alvo, observa-se que, em alguns casos, mesmo a adjetivação parecendo inerente ao subgênero, é comum, depois de certa permanência histórica, determinadas obras quase dispensarem o adjetivo de origem. Que se pense nos clássicos Alice, de Lewis Carroll, Pinóquio, de Carlo Collodi, Peter and Wendy, de James Matthew Barrie. No Brasil, se não há ainda obras da chamada literatura infantojuvenil que atingiram esse patamar de universalização, podem-se observar diversos autores que adquiriram relativa autonomia em relação ao seu nicho original de produção: Monteiro Lobato, Ana Maria Machado, Lygia Bojunga Nunes. Essa constatação, no entanto, não elimina a questão da literatura adjetivada quando se considera o público infantil ou juvenil.

De um modo ou de outro, essas questões estão presentes nas análises constantes do livro. O universo das obras contempladas aqui é restrito, mas serve como indicação de aspectos a serem considerados na produção literária juvenil como um todo. Espera-se que, à medida que essa produção se intensifique, mais fácil será caracterizar teoricamente o subgênero. Enquanto não for possível falar de clássicos juvenis brasileiros, o que tornaria secundária a preocupação em caracterizá-los e avaliá-los como tais, é válido o trabalho de mapeamento e análise da produção mais significativa que circula 
no mercado editorial brasileiro sob o rótulo de literatura juvenil. É dessa perspectiva que são estudados a seguir os livros Açúcar amargo (1986), de Luiz Puntel, As meninas da Praça da Alfândega (1994), de Sérgio Capparelli, De Paris, com amor (1997), de Lino de Albergaria, Antes que o mundo acabe (2000), de Marcelo Carneiro da Cunha, A órbita dos caracóis (2003), de Reinaldo Moraes, e Lenora (2008), de Heloisa Prieto. Por fim, cabe reiterar que, se a análise desses livros vem associada à sua leitura em sala de aula, é porque, de alguma forma, o subgênero literatura juvenil alimenta-se do universo escolar e a ele costuma retornar como alimento de jovens leitores. 